\title{
An Empirical Analysis of English Learning Process and Impact Factors of Open Distance Education
}

\author{
Hongxia Cen \\ Zhejiang Radio \& TV University, Hangzhou, China \\ Email: 1057987728@qq.com
}

Received 22 May 2015; accepted 8 June 2015; published 16 June 2015

Copyright (C) 2015 by author and OALib.

This work is licensed under the Creative Commons Attribution International License (CC BY). http://creativecommons.org/licenses/by/4.0/

(c) (i) Open Access

\begin{abstract}
${ }^{1}$
With the whole process of English learning as a research perspective, the relationship among adult English learners' social situation, motivation, learning strategies and learning effects based on self-determined motivation theory and language learning strategy theory is explored in the study. The findings are obtained through empirical analysis, and the teaching feedback, through which some suggestions are put forward, including constructing autonomy-supportive social situation in order to improve the effect of distance English teaching, improving learning motivation by solving the practical problem, perfecting the corresponding teaching strategies and realizing the learning effectiveness [1].
\end{abstract}

Keywords

Open Distance Education, Adult Students, Impact Factors

Subject Area: Education

\section{Introduction}

English course is a required subject for adult students in the Open University. Distance education separates teachers from students; students are all part-time students who have various abilities. During teaching process, it easily causes students' anxiety and confusion. To improve adult students' English ability, we should not only improve the online technology and application technology, and modern network information communication, but also build self-decided learning atmosphere, improving English learning experience and learning effect. Existing research thinks that learning motivation and learning strategies are the direct factors affecting English

${ }^{1}$ Notes: Education department of Zhejiang province research project: The Research on the Teaching Mode of English Course "Service Study in the Background of open University, one of the series of the results. 
learning. However, if the students have strong motivation, they don't have right way to learn to cooperate; the effect will always discount. Learning motive is the initial cause of students' learning motivation, and learning strategies to certain learning objectives by means of unlike native language learning motivation of learning foreign language is often influenced by external environment, so as an adult student, to study the social situation is also particularly important. Self-determination motivation theories in this research according to the theory of learning (Ryan and Deci, 2000) and the theory of language learning strategies (Oxford, 1990) [2], teaching from the perspective of the whole process of learning, turn to induction, subject design, questionnaire survey and empirical analysis, to explore TV university adult students' social situation of learning English, learning motivation, learning strategy, learning effect, and the relationship among the adult students to improve English teaching effect.

\section{Relevant Concepts and Theories}

\subsection{Social Situation and Social Situation of Learning Foreign Language}

Social situation refers to the individual in the environment. Self-determination theory is that people there are three basic psychological needs - autonomy, the relationship between feeling and the feeling of competence. As long as the environment for individual can support or the social situation of the three psychological needs, which will help to intrinsic motivation and the regulation of the ascension or extrinsic motivation internalization. So, self-determination theory to social situation will be divided into three broad categories: autonomy support, competence support, relationships, relatedness support. Independent support type refers to people with authority status (e.g. teachers), can pay attention to others (e.g. students) point of view, select information and opportunities, and try to avoid stress and command, make each other voluntary to produce action. Competent support type refers to the teacher let the students feel self ability, and confidence can reach even exceed certain external goals or standards. Relationship support type is importantly connected to another person, or makes individuals feel and close feeling, such as high school students in the classroom and the teacher can feel each other's love and care.

In terms of English learning, social situation of students' English learning is created by English teachers' teaching behavior situation or atmosphere. In recent years, the application of self-determination theory, according to a study in the education than be controlled by independent inspire students to inspire students to perform at a higher or better academic achievement, creativity, emotions and self value, intrinsic motivation, also more willing to accept the challenge. And compared with the control model of teachers, support teachers, to student's academic achievement, positive emotions, conceptual understanding, more beneficial self-esteem, creativity, and memory, etc. (Guay and Vallerand, 1997; Reeve, 1997; Reeve and Jang, 2006; Williams and Deci, 1996) [3]. Reeve induction summarizes two conclusions: one is being independent can inspire students succeed and progress, it is to support students' autonomy in learning helps students.

Student learning environment is mainly for the family and school, Noels, Clement and Pelletier (1999), and Kimura, Nakata and Okumura (2001) pointed out that the teacher is the key to influence language learners' characters, this study choose the social situation created by teachers as research point.

\subsection{The Self-Determination Theory and Its Use in Foreign Language Learning}

Self-determination Theory (Self-determination, SDT) is a development, by the American scholar Deci and Ryan is discussed the difference between intrinsic motivation and extrinsic motivation and social situation for the intrinsic motivation of the catalytic effect is relatively complete Theory (Ryan and Deci, 2000). Self-determination theory mainly discusses topics include: define different types of motivation, as well as each kind of motivation for learning, performance, personal experience and the different effects of health; Discuss factors promote or hinder the intrinsic motivation of social situation; Analysis of self adjustment, explore how people are influenced by social values as well as the external situation, and gradually to transform the external control become personal values and self motivation (Ryan and Deci, 2000). Self-determination theory, the motivation is divided into six kinds: no motive (a motivation), external regulation motive (externally regulation), projection adjustment motives (interjected regulation), identity motives (identification) regulation, integration adjustment motives (integrated regulation) and intrinsic motivation (intrinsic regulation). No motivation refers to the learners 
lack the intention to learn English, don't expect to gain their own learning and what kind of results. External regulation motivations refer to the learners because of the influence of other people's thoughts or external rewards, punishment, behavior and adjust their learning English. Projected self-adjustment motivation refers to the learners in order to demonstrate the ability to maintain personal sense of value, or to avoid failure and feel ashamed myself learning behavior generated by the regulation. Agree to adjust motivation refers to the learners aware of the importance of English learning, can achieve some of the tools, and adjust their learning behavior. Fusion regulation refers to the learners not only to detect the value and importance of learning English, and put it into personal values. Intrinsic motivation refers to the learners' inner satisfaction, pleasure, or for personal interest and behavior generation.

English learning motivation is to point to directly promote students in English learning of an internal power, is to motivate and guide students in English learning a kind of need. Look from abroad for research to improve language learners' learning effect, not only to analyze from the aspects of learners' motivation types, but also explore learners' background and foreign language teachers' classroom social situation created by types of motivation such as before because of variables, and motivation to influence the consequences of the variables involved. Referred to in this study of English learning motivation is based on self-determination Theory (Self-determination, SDT) on the basis of learning motivation.

\subsection{Learning Strategies and Language Learning Strategies}

Wenden and Rubin (1987: p. 19) thinks that learning is learner strategies for the extraction of acquisition, storage, and use of information taken any operations, procedures, plans. Oxford $(1990,2001)$ believes that learning strategies that learners take specific actions, behaviors, steps, or techniques, etc., to make learning easier, faster, more enjoyable, more effective and more able to migrate to new situations. Learning strategies that taken by learners in the learning process, in order to promote learning and learning behavior. Learning strategies play an important role in English learning, English learning strategy refers to learners of English in order to improve the effectiveness and efficiency of English learning, purposefully and consciously develop complex schemes about the English learning process. This research adopts the theory is being widely applied linguistics of American scholars Oxford (1990) the development of language learning strategy system, the system for the memory, cognitive, compensation, met cognitive, affective and social level, six in this system, language learning strategies are divided into two broad categories - direct and indirect, direct strategy subdivided into memory, cognitive and compensation of three parts, the indirect strategy is divided into met cognitive, affective and society. Memory strategy refers to using grouping, Lenovo and skills, such as heart as to help students store and extract the new message. Cognitive strategies refer to inductive or deductive and reasoning, make students understand and express the new language. Compensation strategy is to point to by guessing or using synonym lets the student across the lack of knowledge and gaps. Met cognitive strategy refers to the concentration, scheduling, planning and evaluation of learning itself, the cognitive learning process monitoring. Affective strategies refer to assist students to adjust their mood, motivation and attitude. Social strategies refer to help students learn through interaction with others.

\section{Research Methods}

1) The object of study. Select different families in Zhejiang Radio and TV University classes, adult vocational students as participants, to issue 1000 questionnaires, 921 effective questionnaires were taken back, including 578 people in the liberal arts, science and engineering, 343.

2) Research tools. This study adopts questionnaire survey, respectively with adult English learning social situation questionnaire, adult English learning motivation questionnaire and adult English learning strategies questionnaire. English learning social situation questionnaire is for reference to William and Deci (1996). The Learning atmosphere of The scale, The Learning Climate Questionnaire, LCQ) and Seldon Filak demand satisfaction scale (2008) [4], according to The theory of social situation translation, compilation, a total of 9 items, including autonomy, feeling of competence, sense of relationship in three aspects. Adult English Learning motivation Questionnaire reference Ryan and Connell (1989) [5] of Academic self-regulation scale (Academic Self-Regulation Questionnaire, SRQ-A), Learning, Self adjusting scale (Learning Self-Regulation Questionnaire, SRQ-1), [6] [7] according to self-determination theory framework translation preparation, including motivation, external regu- 
lating project motivation, adjust the motivation, recognition fusion motivation, motivation and intrinsic motivation, etc. Adult English learning strategy questionnaire, with reference to Oxford's (1990) language learning strategies questionnaire translation [8]-[10], compilation, including memory, cognitive, compensation, metacognitive, affective and social six aspects. Questionnaire, all questions are in liker scale score's five, each question has five options, participants in total table and subscales score is higher, said the feel the teacher's support degree is higher, with the more motivation. English learning strategy use frequency is higher. Adult students learning effect is the Open University English learning achievement as evaluation standard, divided into below 50, 50 to 59, $60-69,70-70,80-89,90-90$, a total of six groups.

3) Data processing. All data with SPSS19.0 software package for processing [11] [12], the use of statistical methods are descriptive statistics, Pearson correlation, etc.

\section{Results Analysis}

1. Open University adult students social situation in English study, learning motivation, learning strategy, learning effect

\section{1) Open University adult students learning English social situation}

Various parts of the social situation and the average, standard deviation is as shown in Table 1.

Overall social situation from Table 1, the average is 3.50, belong to moderate. In respect of three parts, the independent averages 3.50 belong to medium level; Up to the average of 3.68, belongs to the medium level; Relationship between the average of 3.32, belong to moderate. Was the highest in the aspect of average score, competent, independent second, minimum.

\section{2) Open University adult students' English learning motivation}

Table 2 shows that various parts of the learning motivation and the average, standard deviation, learning motivation overall averages of 3.07 , belong to moderate. And no motivation in terms of six parts, the average is 2.61, belong to moderate; External regulation averages of 2.92, belongs to the medium level; Projected adjustment motives averages of 2.98, belong to moderate; Agree to adjust motivation averages of 3.70, belong to moderate; Fusion regulation motive averages of 3.31, belong to moderate; Intrinsic motivation averages of 2.85, belong to moderate. Was the highest in the aspect of average score, agreed to adjust, adjust times, projection adjust the third, the external regulation of the fourth, fifth intrinsic motivation, no motivation.

\section{3) Open University adult students English learning strategy (Table 3)}

4) Open University adult students' English learning situation (Table 4)

Table 1. Social situation for the mean, standard deviation of each part table.

\begin{tabular}{cccc}
\hline Variable & Question number & Average & Standard deviation \\
\hline Autonomy & 2 & 3.50 & 0.85 \\
Competence feeling & 3 & 3.68 & 0.71 \\
Sense of relationship & 3 & 3.32 & 0.75 \\
Social situation & 8 & 3.50 & 0.66 \\
\hline
\end{tabular}

Table 2. Learning in each part of the mean, standard deviation table.

\begin{tabular}{cccc}
\hline Variable & Question number & Average & Standard deviation \\
\hline No motivation & 4 & 2.61 & 0.85 \\
External regulation motivation & 4 & 2.92 & 0.83 \\
Projection to adjust motivation & 4 & 3.70 & 0.77 \\
Agree to adjust motivation & 4 & 3.31 & 0.75 \\
Fusion to adjust motivation & 7 & 2.85 & 0.66 \\
Intrinsic motivation & 7 & 3.07 & 0.73 \\
Learning motivation & 30 & 0.47
\end{tabular}


Table 3. Learning strategies in all parts of the average, standard deviation table.

\begin{tabular}{cccc}
\hline Variable & Question number & Average & Standard deviation \\
Memory & 6 & 2.75 & 0.67 \\
Cognize & 10 & 2.94 & 0.68 \\
Compensation & 7 & 3.32 & 0.78 \\
Direct strategy & 23 & 3.01 & 0.57 \\
Met cognitive & 5 & 2.97 & 0.79 \\
Affection & 3 & 2.83 & 0.76 \\
Society & 6 & 2.67 & 0.77 \\
Indirect strategy & 14 & 2.81 & 0.69 \\
Learning strategy & 37 & 2.93 & 0.58 \\
\hline
\end{tabular}

Table 4. Effect of learning mean, standard deviation table.

\begin{tabular}{cccc}
\hline Variable & Question number & Average & Standard deviation \\
\hline Learning effect & 1 & 3.95 & 1.35 \\
\hline
\end{tabular}

2. Open University adult students social situation in English study, learning motivation, learning strategy, learning effect of the correlation analysis between

1) Social situation and the correlation analysis between the learning motivations

It can be seen from Table 5 social situation between learning motivation and the correlation coefficient was $0.366(\mathrm{p}<0.0001)$, and the social situation and learning motivation in all parts of the parts, in addition to no motivation and autonomy, competence, relationships, social situations outside of a negative correlation $(\mathrm{r}=$ $0.282,0.451 ; \mathrm{p}<0.001)$, the rest were presented positive correlation $(\mathrm{r}=0.0690 .477 ; \mathrm{p}<0.01)$, motivation and social situation within the highest correlation coefficient $(\mathrm{r}=0.477)$, and project adjustment and up to the minimum correlation coefficient $(\mathrm{r}=0.069)$.

2) The correlation between learning motivation and learning strategies

It can be seen from Table 6, the correlation between the learning motivation and learning strategy was 0.522 ( $\mathrm{p}<0.001$ ), while the learning motivation and learning strategies in all parts of the parts, in addition to no motive and memory, cognitive, compensation, met cognitive, affective and social, learning strategies are outside the present negative correlation $(\mathrm{r}=0.166-0.511 ; \mathrm{p}<0.001)$, the rest of the motivation form with all the learning strategies between present positive correlation $(\mathrm{r}=0.113,0.533 ; \mathrm{p}<0.001)$, after which a cognitive and agree to adjust the highest correlation coefficient $(r=0.533)$, and the society and the projection of adjusting the lowest correlation coefficient $(\mathrm{r}=0.113)$.

3) The correlation analysis between learning strategy and learning effect

It can be seen from Table 7 correlation coefficient was 0.298 between learning strategy and learning effects ( $p$ $<0.001)$, and in all parts of learning strategies and learning results, all showed positive correlation $(\mathrm{r}=0.134$, 0.287; $\mathrm{p}<0.001)$, among them with learning effect and set the highest correlation coefficient $(\mathrm{r}=0.354)$, and the learning effect and the lowest affective correlation coefficient $(\mathrm{r}=0.134)$.

4) The correlation between learning motivation and learning effect

It can be seen from Table 8 , the correlation between the learning motivation and learning effect of $0.154\left({ }^{* * *} \mathrm{p}\right.$ $<0.001$ ), and in all parts of learning motivation and learning effect, in addition to no motivation and learning effect present negative correlation $(\mathrm{r}=0.238, \mathrm{p}<0.001)$, the rest were presented positive correlation $(\mathrm{r}=0.041$, $0.269)$, one identity regulation and the effect of learning the highest correlation coefficient $(r=0.269)$, and project control and learning effect between the lowest correlation coefficient $(\mathrm{r}=0.041)$.

\section{Conclusions}

In Open University, adult students perceive social situation in English classroom. The feeling of competence is 
Table 5. Correlation analysis between learning motivation and social situation.

\begin{tabular}{|c|c|c|c|c|}
\hline & Independent & Qualified & Relationship & Social situation \\
\hline No motivation & $-0.282^{* * *}$ & $-0.451^{* * *}$ & $-0.337^{* * *}$ & $-0.431^{* * *}$ \\
\hline External regulation motivation & $0.219^{* * *}$ & $0.120^{* * *}$ & $0.252^{* * *}$ & $0.267^{* * *}$ \\
\hline Projection to adjust motivation & $0.100^{* * *}$ & $0.069^{* * *}$ & $0.143^{* * *}$ & $0.133^{* * *}$ \\
\hline Agree to adjust motivation & $0.279^{* * *}$ & $0.477^{* * *}$ & $0.349^{* * *}$ & $0.467^{* * *}$ \\
\hline Fusion to adjust motivation & $0.346^{* * *}$ & $0.367^{* * *}$ & $0.388^{* * *}$ & $0.469^{* * *}$ \\
\hline Intrinsic motivation & $0.345^{* * *}$ & $0.465^{* * *}$ & $0.359^{* * *}$ & $0.477^{* * *}$ \\
\hline Learning motivation & $0.267^{* * *}$ & $0.334^{* * *}$ & $0.343^{* * *}$ & $0.366^{* * *}$ \\
\hline
\end{tabular}
${ }^{* * *} \mathrm{p}<0.001$.

Table 6. Learning motivation and learning strategies of correlation analysis.

\begin{tabular}{cccccccc}
\hline Variable & No motivation & $\begin{array}{c}\text { External } \\
\text { regulation } \\
\text { motivation }\end{array}$ & $\begin{array}{c}\text { Projection to } \\
\text { adjust }\end{array}$ & $\begin{array}{c}\text { Agree to adjust } \\
\text { motivation }\end{array}$ & $\begin{array}{c}\text { Fusion to } \\
\text { adjust } \\
\text { motivation }\end{array}$ & $\begin{array}{c}\text { Intrinsic } \\
\text { motivation }\end{array}$ & $\begin{array}{c}\text { Learning } \\
\text { motivation }\end{array}$ \\
Memory & $-0.277^{* * *}$ & $0.213^{* * *}$ & $0.142^{* * *}$ & $0.376^{* * *}$ & $0.345^{* * *}$ & $0.376^{* * *}$ & $0.331^{* * *}$ \\
Cognize & $-0.322^{* * *}$ & $0.198^{* * *}$ & $0.169^{* * *}$ & $0.456^{* * *}$ & $0.362^{* * *}$ & $0.427^{* * *}$ & $0.332^{* * *}$ \\
Compensation & $-0.166^{* * *}$ & $0.188^{* * *}$ & $0.178^{* * *}$ & $0.268^{* * *}$ & $0.273^{* * *}$ & $0.216^{* * *}$ & $0.269^{* * *}$ \\
Metacognitive & $-0.511^{* * *}$ & $0.222^{* * *}$ & $0.236^{* * *}$ & $0.533^{* * *}$ & $0.486^{* * *}$ & $0.477^{* * *}$ & $0.389^{* * *}$ \\
Affection & $-0.266^{* * *}$ & $0.315^{* * *}$ & $0.265^{* * *}$ & $0.391^{* * *}$ & $0.388^{* * *}$ & $0.367^{* * *}$ & $0.427^{* * *}$ \\
Society & $-0.267^{* * *}$ & $0.198^{* * *}$ & $0.113^{* * *}$ & $0.360^{* * *}$ & $0.264^{* * *}$ & $0.344^{* * *}$ & $0.293^{* * *}$ \\
Direct strategy & $-0.332^{* * *}$ & $0.254^{* * *}$ & $0.195^{* * *}$ & $0.441^{* * *}$ & $0.394^{* * *}$ & $0.399^{* * *}$ & $0.368^{* * *}$ \\
Indirect strategy & $-0.385^{* * *}$ & $0.287^{* * *}$ & $0.229^{* * *}$ & $0.484^{* * *}$ & $0.443^{* * *}$ & $0.461^{* * *}$ & $0.425^{* * *}$ \\
Learning strategy & $-0.376^{* * *}$ & $0.238^{* * *}$ & $0.231^{* * *}$ & $0.499^{* * *}$ & $0.449^{* * *}$ & $0.463^{* * *}$ & $0.522^{* * *}$
\end{tabular}
${ }^{* * *} \mathrm{p}<0.001$.

Table 7. Between learning strategies and learning results of related cases.

\begin{tabular}{|c|c|c|c|c|c|c|c|c|c|}
\hline & Memory & Cognize & Compensation & Metacognitive & Affection & Society & $\begin{array}{c}\text { Direct } \\
\text { strategy }\end{array}$ & $\begin{array}{l}\text { Indirect } \\
\text { strategy }\end{array}$ & $\begin{array}{c}\text { Learning } \\
\text { strategy }\end{array}$ \\
\hline $\begin{array}{c}\text { Learning } \\
\text { effect }\end{array}$ & $0.191^{* * *}$ & $0.287^{* * *}$ & $0.166^{* * *}$ & $0.354^{* * *}$ & $0.134^{* * *}$ & $0.171^{* * *}$ & $0.252^{* * *}$ & $0.245^{* * *}$ & $0.298^{* * *}$ \\
\hline
\end{tabular}

Table 8. Analysis on learning motivation and learning effect.

\begin{tabular}{ccccccc}
\hline No motivation & $\begin{array}{c}\text { External } \\
\text { adjustment }\end{array}$ & $\begin{array}{c}\text { Internal } \\
\text { adjustment }\end{array}$ & $\begin{array}{c}\text { Agree to } \\
\text { adjustment }\end{array}$ & $\begin{array}{c}\text { Fusion to } \\
\text { adjustment }\end{array}$ & $\begin{array}{c}\text { Intrinsic } \\
\text { motivation }\end{array}$ & $\begin{array}{c}\text { Learning } \\
\text { motivation }\end{array}$ \\
\hline Learning effect & $-0.238^{* * *}$ & $0.041^{* * *}$ & $0.062^{* * *}$ & $0.269^{* * *}$ & $0.211^{* * *}$ & $0.232^{* * *}$ \\
\hline
\end{tabular}

${ }^{*} \mathrm{p}<0.05 ;{ }^{* * *} \mathrm{p}<0.001$.

the highest, followed by autonomy. The lowest is the relationship; the overall average belongs to medium level. Open University adult students perceive the feeling of competence in the English class situation. As the highest associated with adult students is lack of the confidence of learning English, many adult students learning English before entering the Open University have experience of failure and lose confidence in learning English. So, 
in their English learning, competent support can effectively enhance their self-confidence, to improve the effect of learning English. Relations to get the lowest marks, which may be related to the Open University to be adopted in the teaching of the adult students' English teaching methods, are concerned. Many courses' teaching is in the form of distance education. Interaction of teachers and students in classroom is less relevant.

In terms of learning motivation, in this study, the extrinsic motivation belongs to every level of the average which is higher than that of intrinsic motivation. The overall belongs to moderate learning motivation. Is the Open University still in the adult students' motivation to learn English outside? But in this study, learning motivation scored the highest in the first two, adjustment and consolidation adjustment. In self-determination theory, these two kinds of regulation are seen as a relatively independent or self-determination motivation form, so that although the Open University adult students' English learning motivation belongs to the external, it still has its intrinsic aspects of self decision. And incompletion is caused by external utilitarian incentives. The adult students in the Open University agree that the adjusted score is higher, showing that most of the adult students realize that learning English is important in the work, in order to promote the work and English learning. Higher scores and fusion control may be related to the students in terms of the importance of learning English and gradually produce one kind of aware behavior study. Intrinsic motivation is low with adult students, passive process of learning English is closely linked together, and the purpose of the learning English is just a tool. In this study, with the lowest scores for no motivation, all belong to a low degree. Adult students in the Open University study English for certain purposes and expectations.

In terms of learning strategies, in this study, the Open University adult students use English learning strategy most for compensation strategy. Compensation strategy is mainly by guess to achieve the communication effect. In general, adult students' vocabulary is not large and they cannot fully understand the reading content. So, the application of the compensation strategy is very necessary. What the English teacher teaches in classroom using compensation strategy also has a certain relationship, because the teacher enables students to use probability. Open University adult students use learning strategies for social policy least. Social policy inclusion content is through the interaction among people, or to help achieve the goal of language learning. The common phenomenon of Open University adult students is less willing to take the initiative to speak English. Many adult students tend to pay more attention to the face, so they will feel humiliated if their English is bad. In terms of social situation in English learning, whether in English learning motivation or English learning strategies, this research measures the average of all belonging to the medium level. The Open University creates good English learning environment for adult students to motivate and use strategies where there is room for improvement.

The social situation and learning motivation showed moderate correlation $(\mathrm{r}=0.366)$. In all parts of social situation and learning motivation between the parts of all relevant, the correlation coefficient is the highest intrinsic motivation and social situation $(r=0.477)$, and it also verifies the self-determination theory scholars advocated social situation helps to intrinsic motivation of induce and maintain the point of view. In all positive correlation, projection and adjustment equal to the lowest correlation coefficient $(r=0.069)$, the sequence is projected to adjust and independent $(\mathrm{r}=0.100)$, project adjustment and social situation $(\mathrm{r}=0.133)$, project adjustment and relationship $(\mathrm{r}=0.143)$. Visible, projected to adjust the relationship of different levels of the social situation and degree is extremely low, as for the external regulation and social situation in various parts of the correlation coefficient is less than identity regulation, regulation and intrinsic motivation, learning motivation and social situation the correlation coefficient of each part. According to self-determination theory of motivation continuously bring watch, regulating by the fusion recognition adjustment to the right to self-determination motivation and intrinsic motivation is, the more to the left is the lack of self-determination, so whether external adjustment or project adjustment and social situation of low correlation coefficient of each part, the result is consistent with self-determination theory.

Showed a moderate correlation between learning motivation and learning strategies, based on the learning motivation and learning strategies in all parts of each part of the analysis, found that has no motivation and learning strategies are negative correlation, the parts can be seen that after the student has the less learning motivation, the use of learning strategies, the less the number of it. In all positive correlation, the external regulation and the correlation between the learning strategy in all parts of the project and adjusting and learning strategy between the parts of the correlation coefficient is lower than other motivation and learning strategies of each part related, thus the students learning motivation if tend to be self decision, so he used the more the number of learning strategies.

Positively related learning strategy and learning effect, but also found that low correlation between learning 
strategies and learning effect; Present positive correlation between learning motivation and learning effect, but also found that low correlation between learning strategies and learning effect. Compared learning strategy and learning motivation, learning strategy and learning effect between related to higher than the correlation between learning motivation and learning effect, which can be found that learning motivation can be affect the remote cause of learning, the proximate cause of the learning strategy is directly affect the learning motivation.

In this study sampling condition, get the following results:

1) Open University adult students perceived English classroom's social situation is moderate, with up to support the perception of the highest degree, followed by independent support and relationship support, the Open University is the relationship between adult students support social situation needs to be improved.

2) Open University adult students' English learning motivation is moderate, six kinds of motivation types, the adjustment and integration adjustment on the highest average score, the average scores of intrinsic motivation and motivation, lowest visible external Open University is still in the students' English learning motivation of adult, but still has the intrinsic aspects of self-determination.

3. Open University adult students English learning strategy use frequency is moderate, the Open University adult students most frequently use compensation strategies, in order to met cognitive strategies, cognitive strategies, affective strategies, memory strategies, at least use social strategy, the average scores of each strategy are belong to medium.

4. Open University for moderate adult students' English learning achievement.

5) Social situation showed moderate correlation with learning motivation, in addition to no motivation and autonomy, competence, and negatively correlated with social situation, the rest were present positive correlation.

6) Moderate related learning motivation and learning strategy, learning motivation and learning strategies in all parts of the parts, in addition to no motive and memory, cognitive, compensation, met cognitive, affective and social, learning strategies are present negative correlation, the rest of the motivation form with all the learning strategies between present positive correlation.

7) But low related learning strategy and learning achievement. But low related learning motivation and learning achievement.

\section{References}

[1] Ryan, R.M. and Deci, E.L. (2000) Self-Determination Theory and the Facilitation of Intrinsic Motivation, Social Development, and Well-Being. American Psychologist, 55, 68-78. http://dx.doi.org/10.1037/0003-066X.55.1.68

[2] Oxford, R.L. (1990) Language Learning Strategies: What Every Teacher Should Know. Heinle \& Hernle, Boston.

[3] Williams, G.C. and Deci, E.L. (1996) Internalization of Biopsychosocial Values by Medical Students: A Test of SelfDetermination Theory. Journal of Personality and Social Psychology, 70, 767-779. http://dx.doi.org/10.1037/0022-3514.70.4.767

[4] Sheldon, K.M. and Filak, V. (2008) Manipulating Autonomy, Competence, and Relatedness Support in a GameLearning Context: New Evidence That All Three Needs Matter. The British Psychological Society, 47, 267-283. http://dx.doi.org/10.1348/014466607X238797

[5] Ryan, R.M. and Connell, J.P. (1989) Perceived Locus of Causality and Internalization: Examining Reasons for Acting in Two Domains. Journal of Personality and Social Psychology, 57, 749-761. http://dx.doi.org/10.1037/0022-3514.57.5.749

[6] Guay, F. and Vallerand, R.J. (1997) Social Context, Student's Motivation, and Academic Achievement: Toward a Process Model. Social Psychology of Education, I, 211-233.

[7] Reeve, J. (2004) Self-Determination Theory Applied to Educational Settings. In: Deci, E.L. and Ryan R.M., Eds., Handbook of Self-Determination Research, Soft Cover Edition, The University of Rochester Press, Rochester, 3-33.

[8] Reeve, J. and Jang, H. (2006) What Teachers Say and Do to Support Students' Autonomy during a Learning Activity. Journal of Educational Psychology, 98, 209-218. http://dx.doi.org/10.1037/0022-0663.98.1.209

[9] Noels, K.A., Clément, R. and Pelletier, L.G. (1999) Perceptions of Teachers' Communicative Style and Students' Intrinsic and Extrinsic Motivation. The Modern Language Journal, 83, 23-34. http://dx.doi.org/10.1111/0026-7902.00003

[10] Kimura, Y., Nakata, Y. and Okumura, T. (2001) Language Learning Motivation of EFL Learners in Japan-A CrossSectional Analysis of Various Learning Milieus. JALT Journal, 23, 47-68.

[11] Noels, K.A., Pelletier, L.G., Clément, R. and Vallerand, R.J. (2000) Why Are You Learning a Second Language? Motivational Orientations and Self-Determination Theory. Language Learning, 5, 57-85. 
http://dx.doi.org/10.1111/0023-8333.00111

[12] Noels, K.A., Clément, R. and Pelletier, L. (2001) Intrinsic, Extrinsic, and Integrative Orientations of French Canadian Learners of English. Canadian Modern Language Review, 57, 424-442.

\section{Author's Introduction}

Cen Hongxia, Director of public foreign language teaching and research section, associate Professor. The main research direction: English distance education, business English teaching. 